This item was submitted to Loughborough's Research Repository by the author.

Items in Figshare are protected by copyright, with all rights reserved, unless otherwise indicated.

\title{
“I cannot live without my [tablet]": Children's experiences of using tablet technology within the home
}

PLEASE CITE THE PUBLISHED VERSION

https://doi.org/10.1016/j.chb.2018.12.043

PUBLISHER

(C) Elsevier

VERSION

AM (Accepted Manuscript)

\section{PUBLISHER STATEMENT}

This paper was accepted for publication in the journal Computers in Human Behavior and the definitive published version is available at https://doi.org/10.1016/j.chb.2018.12.043.

\section{LICENCE}

CC BY-NC-ND 4.0

\section{REPOSITORY RECORD}

Hadlington, Lee, Hannah White, and Sarah Curtis. 2019. "“I Cannot Live Without My [tablet]”: Children's Experiences of Using Tablet Technology Within the Home". figshare. https://hdl.handle.net/2134/37268. 
"I cannot live without my [tablet]": Children's experiences of using tablet technology within the home.

Dr Lee Hadlington ${ }^{1 *}$

Dr Hannah White ${ }^{2}$

Sarah Curtis BSc (Hons) ${ }^{1}$

1. Division of Psychology, De Montfort University, Leicester, UK.

2. School of Sport, Exercise and Health Sciences, Loughborough University, Loughborough, Leicestershire, UK.

*Address correspondence to: Dr Lee Hadlington, Division of Psychology, School of Health and Life Sciences, De Montfort University, Leicester, LE1 9BH, UK. Email: Ihadlington@dmu.ac.uk 
Keywords: Parental technology boundaries; technology addiction; home ipad use; social interactions.

Highlights:

- Tensions exist between parents and children regarding domestic tablet device use.

- Varied and covert techniques were reported to evade any parental tablet limitations.

- Many children did not have clear boundaries for their home use of tablet technology.

- For some children tablet use may be problematic as symptoms of addiction were reported.

\section{Abstract}

The current study aimed to examine children's experiences of using tablet technology within the home. Eighteen children aged between eight and nine years old took part in four separate focus group discussions. Thematic analysis revealed three predominant themes: a battle of boundaries, a tool to escape the surrounding world, and an emerging dependency on tablet technology. The data implies that there is a growing dependency on tablet technology use among this age group. The current study also outlines that many children engage in a variety of techniques to circumvent parental limits on their tablet usage. However, other children discussed a lack of clear rules and restrictions for their use of tablet devices. The findings suggest that covert and unregulated use of tablet technology may have a detrimental impact upon children, particularly in relation to reduced social interaction, fatigue and increased family tensions due to excessive usage. Further research of child interactions with a wide variety of digital technology and media is warranted. Such exploration would further our understanding of the potential advantages and disadvantages for such technology use, as well as presenting a pathway to produce more effective guidance on home use. 


\section{Introduction}

Touchscreen devices such as the Apple Ipad have the benefit of being able to make the Internet accessible to all ages, as well as a plethora of other entertainment and communication facilities (Holloway, Green, \& Brady, 2013). Tablet devices present a low maintenance, intuitive platform that requires limited training to use, moving away from competence in generic computer literacy skills (Holloway et al., 2013). In the 8-11 years age range, $86 \%$ of children report having access to a tablet device, with a further $52 \%$ stating that they used a tablet almost every day (Ofcom, 2017).

While engaging with technology such as tablets can support positive learning and communication experiences for children (Blum-Ross \& Livingstone, 2016), problems associated with extensive use have also been acknowledged. Concerns related to the availability, ease of use, and accessibility of digital technology and the potential impact on the general well-being of children and adolescents has generated growing media interest (e.g., The Guardian, 2016). There have also been claims that excessive amounts of screen time in younger generations can disrupt cognitive and social development, create sleep disturbances, and impair well-being (Galpin \& Taylor, 2018). Concerns related to aspects of online safety among children have also been raised (McNally et al., 2018; Livingston et al., 2017). However, Galpin and Taylor (2018) note that there is a significant lack of clear research data on which guidance related to screen-use in children.

There has been much focus on the amount of time children spend engaged in activities on digital devices (often referred to as 'screen time'; Blum-Ross \& Livingston, 2016). However, it has recently been proposed that research should move away from this notion of 'quantity', towards what is termed the ' $3 C^{\prime}$ approach (Blum-Ross \& Livingstone, 
2016). This approach conceptualises the use of digital technology in terms of (a) context where, when and how is digital technology being used, (b) content - what is being watched or used, and (c) connections - whether and how relationships are being formed or impeded (Blum-Ross \& Livingstone, 2016). Previous work by Johnson (2010) had also outlined the importance of understanding the context in which digital technology is being used, arguing for a more inclusive theoretical framework that takes these differences into account.

Acknowledging the role of different environments on children's behaviour and development aligns with Bronfenbrenner's $(1977,1994)$ ecological systems theory, where the importance of understanding "development in context" is outlined (1977; p529). Bronfenbrenner's theory describes child development within the context of interactions between different systems in the child's environment (i.e., micro-, meso-, exo- and macrolevel systems). Specifically, at a microsystem level, the theory explores the relationships between a child and a specific setting where they "engage in particular activities", such as their home (Bronfenbrenner, 1977, p514). In response to the Internet revolution, an additional dimension to the microsystem has been proposed - the ecological technosubsystem (Johnson \& Puplampu, 2008). This subsystem focuses on the interaction between a child and different technologies within their environment (Johnson, 2010) which permits consideration of how technologies are being used within different contexts (Edwards, Henderson, Gronn, Scott, \& Mirkhil, 2017). This highlights the importance of understanding more about how children engage with, and experience using, tablet technologies within contexts such as their home. Within the home environment, children are more likely to choose their own activities and have time for exploration (Murphy \& Beggs, 2003). For example, Johnson (2010) noted that home-based users had more comprehensive and enjoyable experiences, whereas school use was seen as less enjoyable and restricted. 
Exploring the use of digital technology within the home and the issues that arise from such would therefore offer a richer, and perhaps more naturalistic setting for such an examination.

Research has recognised that the rise in use of digital technology by children in the home may in turn be changing their experience of home life. For example, it is the age of 'digital parenting' and subsequently different methods of parental mediation to influence their children's technology use are frequently reported (e.g., social restriction; active mediation; Blum-Ross \& Livingstone, 2016). However, parents report difficulties with the management of children's domestic tablet use (Lewis, 2014), and conflict between parents and children often occurs regarding parental limitations placed on digital media use (Beyens \& Beullens, 2016; Blum-Ross \& Livingstone, 2016; Domoff et al., 2017). Further research has also suggested that extensive use of digital media may negatively impact on home life, as it is linked to a disruption of social functioning and reduced time with family (Beyens \& Beullens, 2016; Domoff et al., 2017; Lee \& Chae, 2007).

In summary, the research examining the use of digital media in children has focused closely on excessive use and the detrimental impacts of such. It is clear that excessive use has been associated with parent-child conflict, particularly when it comes to setting boundaries for use within the home. The growth of the ecological techo-subsystem in the context of the child's developmental journey has also been highlighted as being of central interest. Research exploring the actual experiences of children in the context of their daily use of digital technology is somewhat limited (Galpin \& Taylor, 2018). Developing a clearer picture of the experiences associated with the use of digital technology in the home, as well as the associated issues could lead to effective strategies to help manage screen-use among 
children (Przybylski \& Weinstein, 2017). One key recommendation from previous research is to engage in the use of qualitative methods to explore children's current media practices and their experiences of using digital technology (Galpin \& Taylor, 2018). Therefore, the present study aimed to explore the experiences of children and their home use of tablet technology. Aligned with the ecological techno-system proposed as an extension to Brofenbrenner's (1977) original theory, this study will focus on examining the experiences of children aged between 8-9 years old engaged in using tablet devices within their home environment.

\section{Method}

\subsection{Participants}

Eighteen children ( 7 girls and 11 boys) aged eight and nine years old (mean $=8.4$ years) participated in this study. Participants were recruited from one primary school in Leicestershire and identified themselves as actively using a tablet at home and therefore had knowledge of the discussion topic. Participants formed four mixed-sex focus groups of either four or five children and were assigned pseudonyms. Details of the focus groups are shown in Table 1. 
Table 1: Details of focus groups including participant pseudonyms and ages.

\begin{tabular}{ll}
\hline Focus group number & Participants pseudonyms and ages in brackets \\
\hline Focus group 1 (FG1) & Stuart (8); James (8); Carl (9); Hannah (8); Claire (9) \\
Focus group 2 (FG2) & Liam (8); Alex (8); Sadie (8); Laura (8) \\
Focus group 3 (FG3) & Bonnie (9); Stacey (8); Jay (9); Reece (9); Mason (8) \\
Focus group 4 (FG4) & Joe (9); Oscar (8); Stefan (9); Sophie (9)
\end{tabular}

\subsection{Procedure}

Following University ethical approval, detailed information sheets were given to parents. Where parents provided consent for their child to participate, study information was then distributed to the children inviting them to participate. Children who provided individual consent, in addition to parental consent being obtained, took part in the focus groups.

A series of focus group questions were developed from a review of the literature in digital technology use among children and included questions that probed aspects of daily tablet technology use. Example questions included 'What do you enjoy doing on your iPad?', What do you like to play on the Ipad? Do your parents give you any time limits? (A full schedule of the focus group questions is available on request from the corresponding author). Before the focus groups commenced, questions were also discussed with several experts in the field to check for appropriate wording and their contextual relevance. All focus groups were held at the children's school during school time. Participants were familiar with the researcher due to conducting icebreaker activities. Before the focus group began, for clarity, a brief definition of a tablet was read out to the children as 'a tablet is a thin, portable computer that has a touchscreen control'. During the focus groups, rather 
than using the generic term 'tablets' to describe the technology being used, the label of 'iPad' was adopted as a more appropriate descriptor as this appears as the dominant term used, irrespective of make or manufacturer. Participants were also informed of some ground rules for the focus group discussions such as listening, and allowing one person to speak at a time. Focus groups lasted an average of 17 minutes (range $=16-18$ minutes) and were recorded on a Dictaphone and digital camcorder.

\subsection{Data analysis}

Focus group recordings were transcribed verbatim. Data were analysed using inductive thematic analysis, following the steps outlined by Braun and Clarke (2006): familiarisation with the data; generation of initial codes; searching for and creating themes; reviewing themes; and, refining and naming the themes. All transcripts were reviewed by another member of the research team to check for validity in analysis. No differences were reported in relation to coding, however, following discussions, some themes were expanded to include subthemes.

\section{Analysis}

Participants reported using their tablets for several reasons, these included: talking to family and friends (e.g., Facetime, Facebook, Skype, etc.); playing games; watching films; listening to music; educational uses (i.e., homework and reading); and, going on "the web". In relation to children's experiences of tablet use in the home, the analysis revealed three key themes: 1) A battle of boundaries; 2) A tool to escape the surrounding world; and, 3) An 
emerging dependency on tablet technology. These themes and any subthemes are described below.

\subsection{Theme one: A battle of boundaries}

Several children outlined that their parents set boundaries in relation to the use of their tablets. These tended to focus on the day, time and location when and where tablets could be used. However, many children noted that they were not given any specific parental restrictions on tablet use, commenting that their only limits were "until it dies" (Hannah, FG1) or, "till I get tired" (Alex, FG2). Despite a variation in perceived parental boundaries of tablet use, the notion of challenging boundaries was frequently described. A key focus was on hiding tablet use, with participants reporting engaging in covert behaviours to obtain their tablet and also to continue playing outside of any specified times. Bonnie highlights an awareness of going against her mother's restrictions and the secrecy of her subsequent behaviour to continue to access her tablet at night time:

Bonnie: I wanted to get my tablet but my mum said sleep and then I just creep downstairs and get my tablet.

Researcher: So you go on it when you are meant to be sleeping?

Bonnie: Yeah it keeps me awake.

(Bonnie, FG3).

Several tactics to hide tablet use were reported, such as using headphones, keeping "the volume down so no one hears" (Laura, FG2), or turning "it off when my mum comes" (Stuart, FG1). This highlights that the participants have developed a range of strategies to challenge any perceived technology-related parental boundaries. There was also an awareness of the tension caused by any challenges to, or unwillingness to follow parental boundaries regarding tablet usage. Sadie described the tension between herself and her 
mother when she broke boundaries and was using her tablet while she was supposed to be doing her school work:

"...one time my mum was so cross that I was on my iPad supposed to be doing my homework and I missed all the time from doing my homework." (Sadie, FG2).

Problems with parents enforcing boundaries for tablet use were also acknowledged, particularly in relation to parents being distracted and forgetting to follow through on any specified restrictions. James explains how as a result of his mother's own screen time and subsequent distraction, bedtime rules are not enforced and he is able to continue his tablet use:

James: My mum is always playing on the phone and she loses track of time at my bedtime and I'm still playing on my iPad. And I go to sleep whenever I want.

Researcher: What your mum doesn't realise the time as well?

James: No she keeps on, on her phone yeah, and then I'm playing on my tablet and then she doesn't look up at the time and then I just keep on playing on my tablet and don't even remind her so I get to play on it longer.

(James, FG1).

While James outlines awareness of how his mother's actions can influence his tablet use, he also acknowledges his role in challenging boundaries through choosing not to remind his mother of the time so he is able to play for longer.

\subsection{Theme Two: A tool to escape the surrounding world}

The second theme is comprised of two subthemes, firstly, immersed in another world, and secondly, the tablet as a barrier to social engagement: do not disturb.

\subsubsection{Immersed in another world}

This subtheme reflects the accounts of participants being distracted when using their tablet, including being "too engrossed" and "too carried away". Furthermore, Stuart 
described being so absorbed when using his tablet that he felt as though he loses track of time:

"Sometimes I play for nearly one hour and then it feels like I've played for one second" (Stuart, FG1).

The consequences of over-involvement in playing on the tablet are also reflected by Hannah, as she reports not recognising the other options of play that are available to her:

"Because you get carried away with the game you never noticed that you could go outside." (Hannah, FG1).

Being distracted whilst using a tablet also led some participants to be unsuccessful in attempts to multi-task. For example, Bonnie reports her distraction through tablet use leading to an accident and subsequently being told off:

Bonnie: ...Once when I was getting my food from my mum when she was cooking it, I got told off because I smashed a plate by accident (Jay laughs)

Researcher: Because you were on your iPad?

Bonnie: Yeah

(Bonnie, FG3)

3.2.2. The tablet as a barrier to social engagement: do not disturb.

Tablets were also utilised as a method to seek privacy through intentionally avoiding communicating with others. Reece and Jay describe how they purposefully use their tablets and headphones to stop them hearing the people around them:

Reece: I just can't be bothered to listen to anybody.

Researcher: you just can't be bothered to listen?

Jay: I just wear my beats and put my music on full blast, my mum's like "turn that racket down" so I just turn it up even more.

Researcher: So do you think you get a bit distracted and sometimes you don't hear what they say if you have your headphones on?

Reece: No, I do it on purpose.

(Reece and Jay, FG3). 
Bonnie also expresses a desire not be interrupted when playing on her tablet as she described the challenges of being engaged in conversation by family members when just wanting to play:

"... my little sister was trying to talk to me and my mum was trying to talk to me and I was getting a bit distracted because I really wanted to play on my iPad." (Bonnie, FG3).

\subsection{Theme 3: An emerging dependency on tablet technology}

Theme three was identified due to reoccurring factors in the data such as the compulsive urge to use the tablet and a perception of this technology as being an important aspect in the participants' lives. The theme is comprised of three subthemes: excessive engagement with the recharging process; the nature of tablet attachment; and, difficulty switching off, which are described below.

\subsubsection{Excessive engagement with the recharging process}

Considerable awareness was present about how the battery life of the tablet would limit usage. Consequently, this led to advance planning of when tablets would be charged so that maximum use could be achieved. James describes charging his tablet during the school day so it is ready for use when he comes home:

"...because you've got the whole of the school day so it can be on charge... it's going to be full charged and you can just do whatever you want on it." (James, FG1)

However, despite understanding the need to charge the tablet, several participants expressed difficulty in being able to disengage with the tablet when charging. Participants instead reported that they would sit and observe the tablet whilst charging, despite not receiving any obvious benefit from this process.

Joe: Well mine nearly went down to zero so I couldn't even go on it 
Sophie: If my battery is charging I just normally just sit there let it charge and I just stare at it.

Oscar: Yeah I watch it when it's charging

Joe: Yeah I watch it when it's charging...

(FG4)

\subsubsection{The nature of tablet attachment}

Tablets were clearly viewed as being an important aspect in the participants' lives. Throughout the focus groups, the majority of participants expressed positive feelings relating to their tablet use (e.g., "happy", "excited"). In addition, Hannah (FG1) reported that she didn't see her relationship with her tablet as ever changing: "I don't think l'd ever get tired of my tablet." Negative feelings were also expressed in relationship to any proposal withdrawal from the tablets (e.g., "annoyed", "sad"). Sophie expressed sadness at the thought of not having access to her tablet: "I would feel so sad because I cannot live without my Kindle" (Sophie, FG4).

In addition to the enjoyment of using their tablets, participants also seemed to be protective of their tablets. For a few participants, this meant not taking the tablet outside for fear that it might get broken or they could "crack it", for others this meant keeping the tablet close to them, such as sleeping with it under their pillow. However, Sadie describes how keeping the tablet safe under her pillow also means that she then has more unrestricted access to it:

"But when it is bedtime I keep my iPad under the pillow, under my pillow, when its night midnight I wake up and that's when I play." (Sadie, FG2)

\subsubsection{The difficulty in switching off}

Frequent and regular use of tablets was common, with several participants reporting a difficulty in being able to switch off the tablet and leave it alone. Sophie highlights how she feels the draw of the tablet creates difficulty in switching her tablet off: 
Sophie: I feel attracted to it

Researcher: attracted to it? Ok

Sophie: Yeah I don't get off it.

(Sophie, FG4)

Other participants also reported difficulties in being able to put the tablet down, even to charge. James (FG1) reported leaving the tablet to the latest point ("until it's got one percent") before putting it on to charge. Similarly, Hannah (FG1) explained that she removes the table to use again before it is fully charged when "it's on ten percent I take it off because I can't wait".

An inability to switch tablets off led to many participants reporting playing on their tablets at night time, specifically in their beds. Furthermore, some described physiological issues associated with this usage. For example, Mason (FG3) reported that when using his tablet at night he gets "square eyes", while Oscar (FG4) mentioned that "it makes me sweat in my bed". Furthermore, Hannah described how she once actually fell asleep on her tablet:

"one time I had my kindle I fell asleep on it so my mum had to turn it off for me." (Hannah, FG1)

Disengagement from tablets seemed to occur for mealtimes, however, use would continue afterwards, as reported by Sophie (FG4), "I come off it when my mum shouts but then I go upstairs and then I go back on to it." Sophie also mentioned that she "finishes my dinner so quickly" to be able to get back to using the tablet, whereas Stefan reported that he doesn't have to come off his tablet as he uses it while he eats his dinner:

"... I put my tablet on a book when I eat so I can watch videos" (Stefan, FG4).

\section{Discussion}


The aim of the present study was to explore children's experiences of tablet use within the home. The findings of the current study highlight a variety of themes showing how domestic tablet use influences multiple aspects of the child's everyday life. These themes describe the tensions between child and parent in relation to the use of tablet devices within the home, the sense of immersion and isolation provided by engaging in the tablet, and also, the expression of some elements related to behavioural addiction regarding tablet use, including aspects of withdrawal and mood modification.

The first theme outlines the associated tension that arises between the child's wish to use the tablet and attempts by parents to manage such activities as best they can. The findings also highlight that the children employed a variety of tactics to evade boundaries placed on their tablet use. These strategies often involved an aspect of deception, such as concealing their tablet use. The use of such strategies mirrors the findings of Huh (2014) in relation to digital game play, where it was reported that children would hide away in order to play on their digital devices. Awareness that children employ these types of strategies is an important issue, but the practicalities of providing parents with effective ways to prevent this are more complex.

Another aspect evident in the first theme is that for many children, clear boundaries regarding tablet technology use were mostly absent, supporting the findings of Huh (2014) regarding a lack of rules for digital game play among children. Many parents are reportedly unaware of how best to set boundaries related to the use of digital technology (Ortiz, Green \& Lim, 2011). In addition, there may be a lack of general awareness about how digital technology could be impacting on the lives of children (Jordan, Hersey, McDivitt \& Heitzler, 2006), which may subsequently influence limitations on use. Additionally, it may be the case 
that parents wish to avoid conflict in the home; children acknowledged the tension around technology boundaries within the focus group sessions. In contrast, other parents may believe that boundaries regarding digital technology use are only needed for older children (see Chaudron, 2015), one potential reason why restrictions were not reported by all of the children within the current study. However, even at younger ages unfettered access to digital technology can cause a number of issues, including problems with the developmental of attentional control, academic achievement, reading, and maths abilities (Fuchs \& Woessmann, 2004; Ophir, Nass \& Wagner, 2009; Vigdor \& Ladd, 2010). Considering this, it may be the case that a greater emphasis on parental education of the benefits of regulated digital technology use among children is needed.

The second theme relates to the capacity for tablet technology to form a barrier against the offline world. From the current findings it could be suggested that the children become so immersed when using their tablet devices that they lose conscious awareness of what is going on in the offline world surrounding them. An alternative suggestion could be that the children consciously used their tablets to form an active barrier between themselves and the offline environment, perhaps to escape distractions or to seek out privacy. In both instances there is a critical element of the child becoming fully immersed in the interactive world that the tablet device provides. As a result, children may reduce interactions with the environment and people around them. This links back to the importance of understanding the 'connection' aspect when exploring the impact of digital technology and screen use among children (Blum-Ross \& Livingstone, 2016). In this instance it would appear that digital technology use serves to isolate the child from family life, which may potentially undermine relationships. This has been raised in previous research which outlined that interactions with screen media in children could serve to displace social 
interaction (Haughton, Aiken \& Cheevers, 2015; Radesky, Schumacher \& Zuckerman, 2015). Reducing the opportunity for children to engage in such social interactions has been linked to the potential to impede the development of critical social skills (Kirkorian, Pempek, Murphy, Schmidt \& Anderson, 2009; Radesky et al., 2015). This again highlights the potential negative consequences for lengthy periods of unsupervised engagement in interactive digital technology among children. In addition, parents have expressed worries about technology use and the potential impact on social skills as children are not engaged in activities that involve 'real people' (Lewis, 2014). However, the extent to which unsupervised engagement in digital technology influences the development and maintenance of key social skills or family relationships requires further investigation.

The third theme presents tablet use as an important aspect of the child's life, and shows that children are using language or describing behaviours which are symptomatic of an addiction to digital technology (Griffiths, 1998, 2000; Young, 1998). The checklist for behavioural addiction includes the key elements of salience, mood modification, tolerance, and symptoms of withdrawal (Griffiths, 1996). All of these elements were well represented in the current findings. Some of the children reported that they had lost the capacity to control their urge to play with their tablet causing them to displace important activities such as sleeping and completing home work. Mood modification is also evident, where participants in the focus groups used language showing that removal of tablet technology would result in them experiencing negative affective states. As highlighted in previous research, children's engagement in digital media and technology in the home affords them more freedom to explore content in a naturalistic way (Johnson, 2010). However, it may be that this freedom to explore without barriers such as time limits or supervision related to the content, could be causing a variety of further issues. One element highlighted here is 
the potential for children to develop an addictive attachment to their devices. Another concern which comes from unregulated use of digital devices is associated with the content children may be viewing, raising concerns associated with safety and online risk (Blum-Ross \& Livingstone, 2016).

The present study provides an exploration of daily home tablet use in children and provides a first step in highlighting the key issues which further research should aim to explore. However, there are also some limitations to the study. Although efforts were made to reduce the adult-child dynamic, it is a possibility that some children provided information that was not fully truthful, in order to please the researcher (Punch, 2002). Furthermore, some participants became overexcited at times dominating the conversation that in turn may have prevented other children from providing more detail related to their opinions. However, as the children were familiar with each other, they often probed conversations which provided a more in-depth discussion.

In terms of how the current findings could be used to develop further research, a number of clear avenues are presented. In the first instance further work needs to be done on establishing the potential link between the use of digital technology in the young and the impact on social skills and family relationships. This aspect of 'connection' has often been touted as one of the fundamental concerns for the current generation, but only through engaging in longer term empirical data collection can a clearer understanding be achieved. A limitation of the present study was a lack of focus group data from parents, so that their concerns and issues surrounding digital technology use in the home could be compared to that of their children. This is also flagged as a potential route for further research, particularly when exploring the potential conflict that arises in the home for technology use. 
It would also be interesting to explore how parental use of digital technology in the home serves to impact on their child's impressions about acceptable use and limits.

Another aspect that has been briefly discussed in the context of the current research is the potential for tablet use (as well as aligned digital technologies) to create the potential for behavioural addiction. There is a great deal of research that has already been conducted in this area, but there is a tendency for it to focus on later adolescences and adult age groups. Additional work could also explore whether children of different ages have similar experiences of tablet technology. This would provide a better understanding of any concerns regarding the developmental impacts of tablet technology.

In summary, the present study highlights how children engage in the use of tablet technology within the home. Critically, the emergent themes demonstrated a variety of recurrent issues that the children are experiencing. These elements include tensions between the parent and child in relation to the use of the tablet device, aspects of isolation, withdrawal and symptoms of behavioural addiction. The findings from this current study may be beneficial for developmental experts and parents in relation to the development and promotion of effective technology-related boundaries to promote positive technology use among children. The current findings highlight that children are able to provide a unique perspective on their tablet use and as such, their views should be considered when attempting to develop and implement any boundaries. Families should be encouraged to facilitate discussions about tablet use within the home to increase understanding of how positive and regulated technology use among children can be encouraged. 


\section{References}

Beyens, I., \& Beullens, K. (2016). Parent-child conflict about childrens tablet use: The role of parental mediation. New Media \& Society, 1461444816655099. http://doi.org/10.1177/1461444816655099

Blum-Ross, A., \& Livingstone, S. (2016). Families and screen time: Current advice and emerging research. Media Policy Brief. London. Retrieved from http://eprints.Ise.ac.uk/66927/\%5Cnhttp://blogs.Ise.ac.uk/mediapolicyproject/\%5Cn

Braun, V., \& Clarke, V. (2006). Using Thematic Analysis in Psychology. Qualitative Research in Psychology, 3(2), 77-101.

Bronfenbrenner, U. (1977). Toward an Experimental Ecology of Human Development. American Psychologist, 32(7), 513-531. http://doi.org/10.1037/0003-066X.32.7.513

Bronfenbrenner, U. (1994). Ecological models of human development. In M. Gauvain \& M. Cole (Eds.), Readings on the development of children (2nd ed., Vol. 3, pp. 37-43). Oxford. http://doi.org/http://www.psy.cmu.edu/ siegler/35bronfebrenner94.pdf

Domoff, S. E., Harrison, K., Gearhardt, A. N., Gentile, D. A., Lumeng, J. C., Miller, A. L., ... Miller, A. L. (2017). Development and Validation of the Problematic Media Use Measure: A Parent report measure of the screen media "addiction" in Children. Psychology of Popular Media Culture, 1-15.

Edwards, S., Henderson, M., Gronn, D., Scott, A., \& Mirkhil, M. (2017). Digital disconnect or digital difference? A socio-ecological perspective on young children's technology use in the home and the early childhood centre. Technology, Pedagogy and Education, 26(1), 1-17. http://doi.org/10.1080/1475939X.2016.1152291

Fuchs, T., \& Woessmann, L. (2004). Computers and Student Learning: Bivariate and Multivariate Evidence on the availability and use of Computers at Home and at School.

Galpin, A., \& Taylor, G. (2018). Changing behaviour : Children, adolescents and screen use. The British Psychological Society, 1-6. Retrieved from https://www.bps.org.uk/sites/beta.bps.org.uk/files/Policy - Files/Changing behaviour children\%2C adolescents\%2C and screen use.pdf

Griffiths, M. (1996). Behavioural addiction: an issue for everybody? Journal of Workplace Learning, 8(3), 19-25. http://doi.org/10.1108/13665629610116872

Griffiths, M. (1998). Internet addiction: Does it really exist? In J. Gackenbach (Ed.), Psychology and the Internet: Intrapersonal, Interpersonal, and Transpersonal Implications. (pp. 61-75). San Deigo, CA.: Academic Press. Retrieved from http://search.ebscohost.com/login.aspx?direct=true \&db=psyh\&AN=1998-06638003\&site=ehost-live

Griffiths, M. (2000). Does Internet and Computer "Addiction" Exist? Some Case Study Evidence. CyberPsychology \& Behavior, 3(2), 211-218. http://doi.org/10.1089/109493100316067

Haughton, C., Aiken, M., \& Cheevers, C. (2015). Cyber Babies: The Impact of Emerging Technology on the Developing Infant. Psychology Research, 5(9), 504-518. 
http://doi.org/10.17265/2159-5542/2015.09.002

Holloway, D. J., Green, L. R., \& Brady, D. J. (2013). 0-8 : Young children's Internet use. In Proceedings of the ANZCA Conference (pp. 0-11). Australian and New Zealand Communication Association.

Huh, Y. J. (2014). What makes young children active game players; ethnographic case study. DiGRA, 12.

Johnson, G. M. (2010). Internet Use and Child Development : Validation of the Ecological Techno- Subsystem Internet Use and Child Development Ecological Systems Theory and the Techno-Subsystem, 13, 176-185.

Johnson, G. M., \& Puplampu, K. P. (2008). Internet use during childhood and the ecological techno-subsystem. Canadian Journal of Learning \& Technology, 34(I), 19-28. http://doi.org/10.21432/T2CP4T

Jordan, A. B., Hersey, J. C., McDivitt, J. A., \& Heitzler, C. D. (2006). Reducing children's television-viewing time: a qualitative study of parents and their children. Pediatrics, 118(5), e1303-e1310. http://doi.org/10.1542/peds.2006-0732

Kirkorian, H. L., Pempek, T. A., Murphy, L. A., Schmidt, M. E., \& Anderson, D. R. (2009). The impact of background television on parent - child interaction. Child Development, 80(5), 1350-1359. http://doi.org/10.1111/j.1467-8624.2009.01337.x

Lee, S.-J., \& Chae, Y.-G. (2007). Children's Internet Use in a Family Context: Influence on Family Relationships and Parental Mediation. CyberPsychology \& Behavior, 10(5), 640644. http://doi.org/10.1089/cpb.2007.9975

Lewis, B. (2014). Raising children in a digtial age: Enjoying the best, avoiding the worst. Oxford, England: Lion Hudson.

Murphy, C., \& Beggs, J. (2003). Primary pupils' and teachers' use of computers at home and school Colette Murphy and Jim Beggs, 34(1), 79-83.

Ophir, E., Nass, C., \& Wagner, A. D. (2009). Cognitive control in media multitaskers. Proceedings of the National Academy of Sciences of the United States of America, 106(37), 15583-7. http://doi.org/10.1073/pnas.0903620106

Przybylski, A. K., \& Weinstein, N. (2017). Digital Screen Time Limits and Young Children's Psychological Well-Being: Evidence From a Population-Based Study. Child Development, OO(0), 1-10. http://doi.org/10.1111/cdev.13007

Radesky, J. S., Schumacher, J., \& Zuckerman, B. (2015). Mobile and Interactive Media Use by Young Children: The Good, the Bad, and the Unknown. Pediatrics, 135(1), 1-3. http://doi.org/10.1542/peds.2014-2251

Vigdor, J. L., \& Ladd, H. F. (2010). Scaling the Digital Divide. Working Paper 48, (june), Online computing magazine. Retrieved from

http://scholar.google.com/scholar?hl=en\&btnG=Search\&q=intitle:Scaling+the+Digital+ Divide\#1

Young, K. S. (1998). Internet addiction: The emergence of a new clinical disorder. 
CyberPsychology \& Behavior, 1(3), 237-244. 